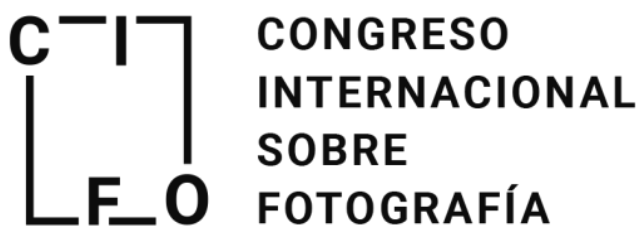

Congreso Internacional sobre Fotografía

UPV, 5 y 6 octubre 2017

Doi: http://dx.doi.org/10.4995/CIFo17.2017.6751

ISBN: 978-84-9048-604-7

\section{La fotografía de arquitectura como objeto de estudio. ¿Convención o supervivencia?}

Mariela Apollonio. Universitat Politecnica Valencia

mariela@fotografadearquitectura.com

\begin{abstract}
'Architectural photography as inherited since the Modern Movement needs to be reconsidered from a new technological and cultural perspective. Architectural photography participates in and forms an integral part of a system of image circulation and consumption where architects and the way their projects are presented or photographed finds itself dominated by mass media. Research must urgently open up new channels of thought that will formulate an architectural photography beyond this inherited system and acknowledge the characteristics of its own specific nature.' This is the purpose of the present text and the result of some of my reflections concerning a discipline I have been developing as a professional photographer for over a decade. What are the inherited conventions? Can there be an architectural photography outside of this inherited system? What would be its means of development? What purpose should an architectural image serve today?
\end{abstract}

Keywords: Architecture, Photography, Investigation, Apollonio, Spain.

\begin{abstract}
Resumen
'Existe una fotografia de arquitectura heredada desde el movimiento moderno que necesita ser revisada en un nuevo contexto tecnológico y cultural. La fotografía de arquitectura participa y se integra en un sistema de circulación y consumo de imágenes en el que los medios de comunicación dominan sobre los proyectos, los arquitectos y sobre la manera de enseñarlos o fotografiarlos. Es imprescindible que desde la investigación se abran nuevos cances de pensamiento que puedan plantear una fotografia de arquitectura más allá de este sistema heredado y se reconozcan cuáles son las caracteristicas de su propia especificidad.'Éste es el propósito del presente texto y el resultado de algunas de mis reflexiones en torno a esta disciplina que desarrollo como profesional desde hace más de diez años. ¿Cuáles son los convencionalismos heredados? ¿Sería posible una fotografía de arquitectura ajena a este sistema heredado? ¿Cuáles serían sus medios de desarrollo?¿Qué propósitos debería perseguir la imagen de arquitectura hoy en día?
\end{abstract}

Palabras clave: Fotografia, Arquitectura, Investigación, Apollonio, España. 


\section{Introducción}

La inseparable vinculación entre fotografía, arquitectura y medios de comunicación, tal y como la conocemos hasta nuestros días, surge con la aparición del movimiento moderno. Esta nueva forma de hacer arquitectura emerge en Europa después de la primera guerra mundial, se establece rápidamente en EEUU antes de la segunda guerra, y consigue dar a conocer sus principios por todo el mundo a través de los medios de comunicación. Los arquitectos comienzan a utilizar los medios como una herramienta para difundir los ideales del nuevo movimiento y sus posibles modos de vida, con el fin de llegar a un público más amplio y no necesariamente especializado. Los estudios de arquitectura empiezan, por primera vez, a tomar consciencia del gran potencial de la arquitectura en los medios y comienzan a diseñar sus edificios teniendo en cuenta su representación. Es decir, a pensarlos en términos de fotografias. El gran público empieza, por primera vez, a sentirse identificado con la arquitectura a través de fotografias publicadas en revistas.

Muchos fueron los fotógrafos responsables de la difusión de estas arquitecturas. Ken y Bill Hedrich-Blessing trabajaron en Chicago y colaboraron para arquitectos como Mies Van der Rohe o Frank Lord Wright. Erza Stoller estableció su estudio en Nueva Yotk y colaboró con grandes arquitectos como Marcel Breuer, Eero Saarinen, Richard Meier o Mies Van der Rohe. Pero quizás el caso más ejemplifícame de este vínculo fue el del fotógrafo Julius Shulman y su participación en el programa Case Study Houses (1945-1960) desarrollado en la costa este de Estados Unidos. John Enteza, director de la revista Arts \& Architecture, fue quien creó el programa y Juluis Shulman fue el encargado de fotografiar 18 de las 26 viviendas diseñadas por arquitectos modernos. La publicación supuso un impulso decisivo para dar a conocer los diseños vanguardistas de California en todo el mundo. El programa consuma las aspiraciones mediáticas, promocionales y comerciales de diseñadores, editores, constructores y clientes. Shulman consigue a través de sus fotografías prototípicas, que la arquitectura moderna pareciese accesible para un gran público no especializado. ${ }^{1}$

\section{La fotografía de arquitectura como institución}

La fotografía de arquitectura como institución es la manera de hacer fotografía a causa de la posición que ocupa ésta dentro de una práctica institucionalizada, en este caso, la arquitectura. Se trata de un modus operandi definido por un conjunto de características que poseen un estatus: el estatus de fotografia de arquitectura. En este sentido, la fotografía de arquitectura, no puede existir en un vacío acontextual sino que existe dentro de una matriz cultural, un marco. Un marco que hace a la vez de púlico. El fotógrafo de arquitectura está siempre implicado en un público dentro del marco de la arquitectura y deberá hacer el tipo de fotografía que este público espera. Este tipo de fotografia es, a fin de cuentas, una convención creada dentro de un sistema que, en el caso de la fotografía de arquitectura, es identificable a través de ciertos aspectos formales y técnicos.

Con todo ello, me atrevería a afirmar que la convención de la fotografía de arquitectura, es contextual, estética y mediática y nos viene dada desde el movimiento moderno.

Pero ¿Qué es una convención? Una convención es una comprensión compartida por todos los implicados en esta práctica establecida, dentro de la cual, existe un complejo de roles interrelacionados. El del arquitecto, el del fotógrafo, el del editor, el del consumidor. Esta imagen existe en un mundo de consensos y cumple una función. El fotógrafo de arquitectura deberá comprender la idea del medio en el que trabaja para lograr un estatus o una

\footnotetext{
${ }^{1}$ Catálogo Fisher Gallery para exposición en Club Diario Levante. 1998. Los Ángeles Obscura: La fotografia arquitectónica de Julius Shulman. Los Ángeles: Universidad de Southern California.
} 
posición dentro de el, es decir, comprender sus convenciones y aplicarlas para ser aceptado dentro de este sistema. $^{2}$

\section{La imagen mecanismo}

Una de las cuestiones más importantes de este momento de confluencia entre fotografía, arquitectura y medios de comunicación es que surge lo que entendemos hoy como fotografia de arquitectura. Una imagen a través de la cual la arquitectura deberá ser representada y expuesta para cobrar significado como medio de comunicación. Se instaura un modo de hacer, una disciplina de normas propias que llamaré la imagen mecanismo. La imagen mecanismo goza hoy de su máximo estado de plenitud. La imagen mecanismo es una imagen sin autor, una imagen plana en su forma y función y está inserta en la estructura de un sistema. Reivindica la cámara y su mecanismo de producción de imágenes claras, transparentes, anodinas y sobretodo carentes de cualquier rastro de subjetividad o posicionamiento. Sus objetivos son explícitos, lineales, previsibles y están regidos por las mismas normas que rigen los intereses de los medios de comunicación de masas o la publicidad. Es un envoltorio en el que no importa lo fotografiado ya que su tratamiento permanece en la superficie. El círculo que conforma esta imagen mecanismo, está formado por el arquitecto, el fotógrafo y el medio especializado. A la imagen mecanismo no le importa la arquitectura, su principal objetivo es, parecerse a otras imágenes mecanismo. La imagen mecanismo es un medio, no un lenguaje.

\section{La imagen mecanismo versus reder}

La imagen mecanismo convive con el render, una imagen realidad que antecede a la realidad construída y que simula las características de las antiguas fotografías. Se establece así, un círculo de influencias en el que ya no podemos diferenciar con claridad la realidad de la ficción. El render simula a la fotografía, la fotografía simula el render.

La fotografía de arquitectura participa y se integra en un sistema de circulación y consumo de imágenes en el que los medios de comunicación dominan sobre los proyectos, los arquitectos y sobre la manera de en señarlos o fotografiarlos. Imágenes que no tienen soporte físico y que circulan como información por nuestras pantallas y dispositivos.

El fotógrafo de arquitectura se ha convertido en un productor de imágenes publicitarias que ahonda en la fotogenia del edificio y no necesariamente en su complejidad o significado. En este contexto, el fotógrafo de arquitectura acaba siendo arquitecto en la construcción de imágenes digitales que serán consideradas arquitecturas. La imagen mecanismo se ha convertido en otra arquitectura con la que la arquitectura de los fenómenos y la materialidad no puede competir.

Con todas estas cuestiones cabría preguntarse ¿La imagen mecanismo representa el valor cultural que queremos proyectar de la arquitectura de hoy? ¿Sería posible pensar en una fotografía de arquitectura más allá de esta convención?

\section{Histéresis fotográfica}

La histéresis es un término que se utiliza en la física para describir la tendencia de un materiala conservar su forma y sus propiedades en ausencia del estímulo que la ha generado. Es la cualidad de ciertos materiales que al presionarlos conservan la forma de esa fuerza. Hace tiempo que en ciertos ámbitos se teoriza sobre la necesidad de una nueva manera de hacer fotografía de arquitectura. Sin embargo, mi impresión en el ámbito profesional,

\footnotetext{
2 Dickie, George. 2005. El Círculo del Arte. Barcelona: Ediciones Paidós Ibérica, S.A.
} 
es que seguimos viviendo en el pasado. En una especie de histéresis fotográfica. No existen propuestas alternativas al sistema. La imagen de la arquitectura demanda un cambio de paradigma, un cambio estructural que derribe las antiguas normas de representación de la arquitectura. Hablo de otras formas de representación y fundamentalmente otros medios dónde desenvolverse. Es decir, nuevos aliados con los que contar.

\section{Supervivencia}

Existe una enorme necesidad desde la investigación de analizar esta imagen mecanismo heredada en un nuevo contexto tecnológico y cultural en el que la imagen de arquitectura, convive con multitud de imágenes que carecen de referente y se desenvuelven de manera hiper acelerada en múltiples plataformas. Es imprescindible que desde la investigación se abran nuevos cauces de pensamiento que puedan plantear una fotografía de arquitectura en la que se reconozca su propia especificidad. La fotografía de arquitectura debe sufrir un proceso autoreflexivo si quiere ser algo más que una simulación o un medio utilitarista. El fin de esta nueva propuesta, no serán los intereses promocionales sino sus propias problemáticas. ¿Es posible pensar en una fotografía de arquitectura que genere nuevas formas de relato? ¿Cuáles serían las características de esta imagen? ¿Qué propósitos debería perseguir la imagen de la arquitectura?

Estos son, a mi ver, los retos actuales que deben analizarse desde la profesión, la investigación y la crítica de la arquitectura y su imagen. 